Prepared in cooperation with the

National Oceanic and Atmospheric Administration

\title{
Sun-illuminated sea floor topography of Quadrangle 3 in the Stellwagen Bank National Marine Sanctuary off Boston, Massachusetts
}

By Page C. Valentine, Jessica L. Baker, and Tanya S. Unger

Geologic Investigations Series Map I-2703

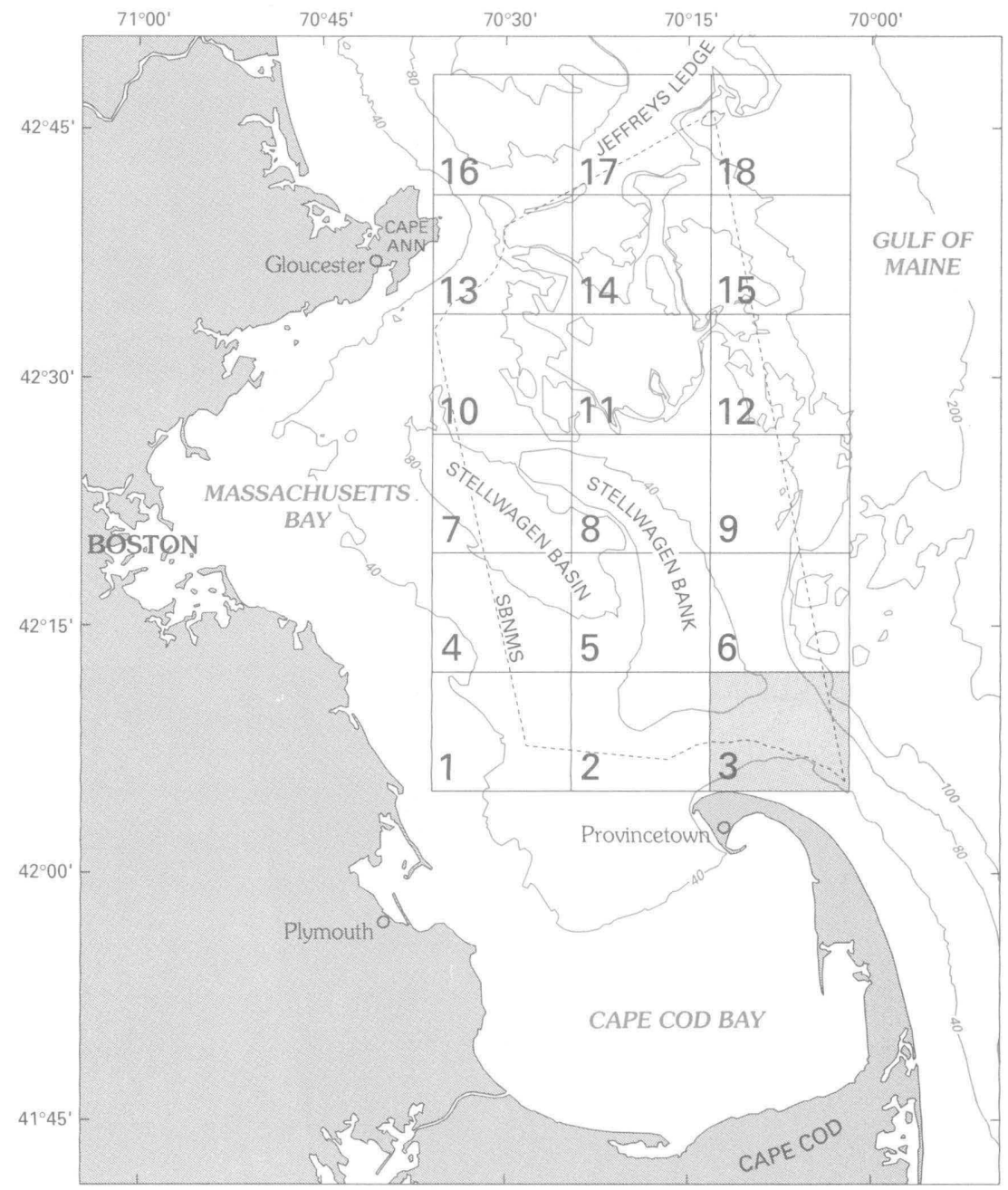

